\title{
INVERTED CLASSROOM IMPROVES PRE-UNIVERSITY STUDENTS UNDERSTANDING ON BASIC TOPIC OF PHYSICS: THE PRELIMINARY STUDY
}

\author{
Elnetthra Folly Eldy*iD, Jackson Chang Hian Wui (iD), Siti Nazirah Butai (iD, \\ Nur Fadzilah Basri (iD), Huzaikha Awang $(\mathbb{D}$, Wardatul Akmam Din (D), \\ Sazmal Effendi Arshad iD
}

Preparatory Centre for Science and Technology, University Malaysia Sabah, Jalan UMS, 88400 Kota Kinabalu, Sabah (Malaysia)

*Correspondingauthor:elnettbra@ums.edu.my,jacksonchw@ums.edu.my,siti.nazirah@ums.edu.my, dilabasri@ums.edu.my,buzaikha.ikha@ums.edu.my,wardadin@ums.edu.my,sazmal@ums.edu.my

Received November 2018

Accepted April 2019

\section{Abstract}

This paper discusses the effectiveness of the inverted classroom implemented in a pre-university physics classroom on topics of classical mechanics. Inverted classroom moves from traditional lectures to providing students with pre-recorded lectures and other materials such as videos, online quizzes and online exercises to foster independent learning. In this study, the classroom was divided into two groups: a control group and experimental group intervened with the inverted classroom; in evaluating the efficiency of the intervention, at the end of the module, both groups were tested using tests that are similar. The findings show that there was a significant difference between control group and experimental group on their pre-test and post-test score. It implies the potential use of this approach in other basic topics of pre-university physics classroom.

Keywords - Inverted classroom, Blended learning, Pre-university, Physics, Classroom.

\section{To cite this article:}

Eldy, E.F., Chang, J.H.W., Butai, S.N., Basri, N.F., Awang. H., Din, W.A., \& Arshad, S.E. (2019). Inverted classroom improves pre-university students understanding on basic topic of physics: The preliminary study. Journal of Technology and Science Education, 9(3), 420-427.

https://doi.org/10.3926/jotse.599

\section{Introduction \& Literature Review of Inverted Classroom in Physics}

Blended learning in higher education has become increasingly popular where it uses technology to move lectures outside the classroom and uses learning activities to move practice with concepts inside the classroom. The concept behind blended learning is to take the best elements of in-person classroom instruction and online instruction and combine them as one. In a blended learning classroom, students attend classes in person and watch pre-recorded lecture videos or complete online activities. It has 
become extremely popular in higher education settings as it allows greater flexibility for students and encourages non-traditional students to pursue higher education. Over the years, it has gained its popularity in many higher education institutions and leads to the introduction of the inverted classroom.

A group of economics professors introduced inverted classroom (IC) formerly known as the flipped classroom from Miami University, Ohio (Talbert, 2012). The main idea of the inverted classroom is the schoolwork is done at home and homework is done at school (Chua \& Lateef, 2014). Garza (2014) summarized the definition of the inverted classroom into two components, one is delivering the lecture through some electronics, and this means the lecture is moving outside the class, two is moving the practical applications such as assignments and homework into the classroom. In this study, the approach of the inverted classroom is consistent with Baepler, Walker and Driessen, (2014) where the lecture is moved to online to be viewed by students before class, and classroom time is purposeful for learning activities that involve students in solving the problem and engaging the concepts they learnt into problem situation.

In South East Asia region, the inverted classroom has been introduced for some years, and its popularity in class is growing in line with the rapid development of technologies (Bishop \& Verleger, 2013). Mason, Shuman and Cook (2013) shared the three main catalysts to implement IC. It allocates class time for interactive activities which allows an educator to present materials of topics without any shortcut. It also allows the educator to present materials in various forms (i.e., video, online forum, reading materials) suitable to students' capacity and lastly students' self-learning drives it. The goal of an inverted classroom is to encourage students who are usually disengaged in their learning and rely more on copying notes, focusing on facts and immediately jumping to conclusions without any judgment (O'Flaherty \& Philips, 2015). Baepler et al. (2014) also emphasized that the students' satisfaction towards their learning for physics is higher when the inverted classroom was implemented over the traditional approach.

In classical mechanics, the study of object's behavior under an applied force such as external force, gravitational force, electromagnetic force and as well as nuclear force is among the scope encompassed in physics (Brown, 2013). It is one of the fundamental topics that student have to master in learning physics. In the pre-university level, students learn about this concept in two important topics which are Work, Energy and Power and the second is Force, Momentum and Impulse. This crucial concept is about the environmental phenomena which are always applied in student daily life and had been learnt by the student since their secondary school. However, the student often find it difficult to master this crucial topic for a variety of misconceptions among them (McDermott \& Redish, 1999). In traditional physics classroom, this topic is often taught by giving a lecture in a lecture hall which involves direct instruction to students, some might be blended with video or audio from various sources to help students relate the idea of topics, and some might provide frequent exercises and assignments (Cagande \& Jugar, 2018). Among the challenges that hinder the study or teaching of physics are students attitudes, as students often do not see relevance the course to their major; mathematical challenges, as students general lack of math skills and students preparedness, as students do not read or know how to read the physics textbook.

With an inverted classroom, active learners are one of the results expected through this approach (Uzunboylu \& Karagözlü, 2017). It focuses more on developing students' skills than on transmitting information and requires students to do something, i.e. read, discuss, and write that requires higherorder thinking (Baepler et al., 2014). They also tend to place some emphasis on students' explorations of their attitudes and values especially on their motivation towards learning. Motivation among physics students will increase their preparation for class, support their reading skills and increase their emphasis on conceptual understanding instead of worrying the mathematical aspect of physics. Capone, Sorbo and Fiore (2017) also agreed that the use of an inverted classroom under challenging topics such as quantum mechanics is beneficial to students. By that, in this study, we used a mixed-method comparative study of two pre-university level physics classrooms: one of them inverted and the other is 
controlled by traditional lecture-homework classroom. The main objectives of this study focus on determining whether there are significant differences in the academic performance between the control group and the experimental group with the change of intervention in which the central axis is studentcentred.

\section{Methods}

The course "SF0014: Mechanics and Thermal Physics" is a first semester course in Foundation of Science Program at the Univesiti Malaysia Sabah, compulsory for all pre-university students. The program is offered annually, and the population is approximately represented in a total course cohort of around 300 students every year. All students are compulsory to take four core subjects, i.e. Physics, Mathematics, Chemistry and Biology during their pre-university level. The students are mainly targeted to feed into undergraduate science program of the university upon the completion of their one-year foundation study.

The whole class lectures of 2 hours duration take place once a week for one lecture group usually consists of 75-80 students. These are supplemented by 1-hour weekly tutorial session, in which students develop a range of skills, both discipline-specific and also more general in small groups of approximately 20-25 per tutorial group. The tutorial session usually takes 1-hour duration where 10-15 questions are given after the lecture and discussed in the tutorial. The course does not have a laboratory component, but another standalone course "SF0011: Practical Physics I" is specially catered for laboratory activities which are taken by all students in the same semester.

\subsection{Subjects and Setting}

A total of 76 pre-university level students in Foundation of Science Program, University Malaysia Sabah were selected in this study, with 43 persons for experimental and 33 persons for the control group. The control group students underwent the teaching-learning process through traditional methodology, in which the lecturer presents the information through typical lecture via multimedia format and carrying out simple, practical activities related to the topics. The practice is very similar to many traditional physics classroom in most of the local pre-university level education institutions.

The topics involved in this study are Work, Energy \& Power, and Force, Momentum \& Impulse. Both topics emphasise different approaches in physics mechanism and have different common misconceptions. The comparison between these topics is summarised in Table 1.

The chronology of educational modalities provided to the students is shown in Figure 1. Two groups of students were provided with similar notes. The different is, students in the traditional classroom attend the lecture as usual meanwhile students in inverted classroom self-study at their own pace and time. Both groups have their extra exercise either by practice problem during a lecture or online quiz and online practice problems. At the end of the implementation, both groups are provided with assessment through problem-based learning (PBL).

\begin{tabular}{|l|l|l|}
\hline \multicolumn{1}{|c|}{ Topics } & \multicolumn{1}{|c|}{ Work, Energy \& Power } & \multicolumn{1}{c|}{ Force, Momentum \&Impulse } \\
\hline Quantity & Deals with scalar quantity & Deals with vector quantity \\
\hline \multirow{2}{*}{ Misconception } & $\begin{array}{l}\text { Students often confused the negative sign } \\
\text { in scalar quantity represents the direction }\end{array}$ & $\begin{array}{l}\text { Students often unable to relate the vector analysis } \\
\text { to solve resultant force at x-component and } \\
\text { y-component }\end{array}$ \\
\cline { 2 - 3 } & $\begin{array}{l}\text { Students also often failed to understand the } \\
\text { change of energy produces work; power is } \\
\text { the rate of the change of energy }\end{array}$ & $\begin{array}{l}\text { Students also often failed to understand the change } \\
\text { of momentum produces force; impulse is the force } \\
\text { applied to an object for a certain of time. }\end{array}$ \\
\hline $\begin{array}{l}\text { Important } \\
\text { Concepts }\end{array}$ & $\begin{array}{l}\text { Work-energy theorem } \\
\text { Conservation of energy }\end{array}$ & $\begin{array}{l}\text { Newton's law of motion } \\
\text { Conservation of momentum }\end{array}$ \\
\hline
\end{tabular}

Table 1. Comparison of two essential topics in physics 


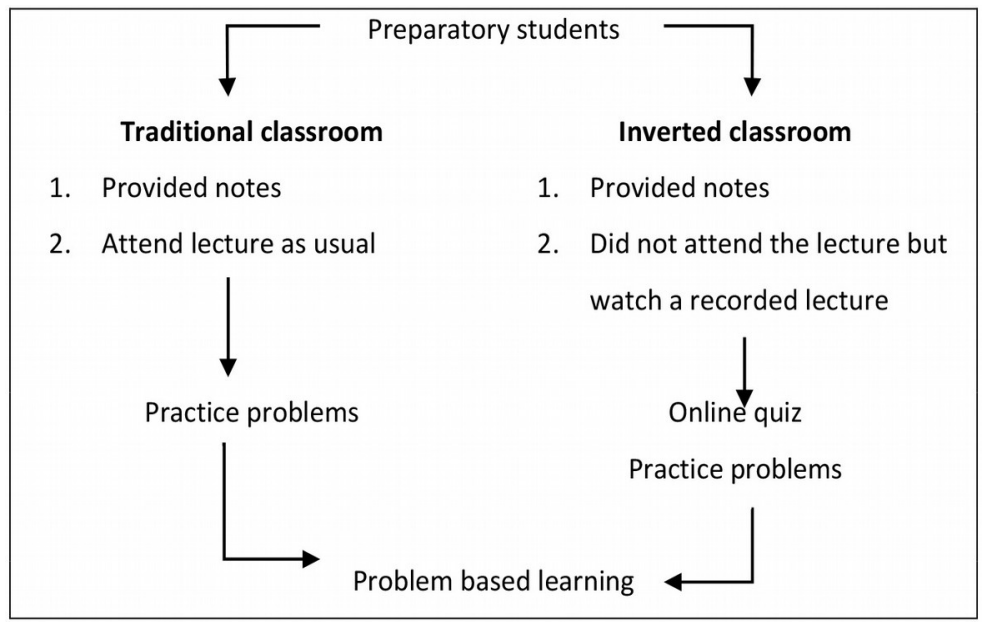

Figure 1. Chronology of educational modalities provided to students in traditional versus inverted classroom

\subsection{Study Design \& Implementation}

Figure 2 shows all the contents offloaded from lecture videos to self-paced online videos for the experimental group in this study. Padlet was used as the medium to share all the materials. The goals were to provide students with fundamental concepts before class, create opportunities for students to apply the concepts they learn through exercises provided in the form of an example of questions and online quizzes. Assessment in the inverted classroom was done by problem-based learning (PBL) which is expected to help on the fostering of critical thinking skills and problem-solving skills.

The four steps in Physics PBL are described as follow, also used for the traditional classroom.

Step 1 (Students presented with a real-life problem). Students are introduced to the scenario of the problem after self-centred learning on the topics. Before they split into their respective group, the facilitator provides an introduction and explanation of the problem.

Step 2 (Students understand, research and solve the problem within the group). In this step, an adaptation from seven steps of Maastricht for Problem-based learning approach is used as a step to step guide to solve the problem. The seven-steps includes clarifying and defining terms, defining a scenario of the problem, analyse, structuring objectives and hypothesis, searching for information and exchanging information.

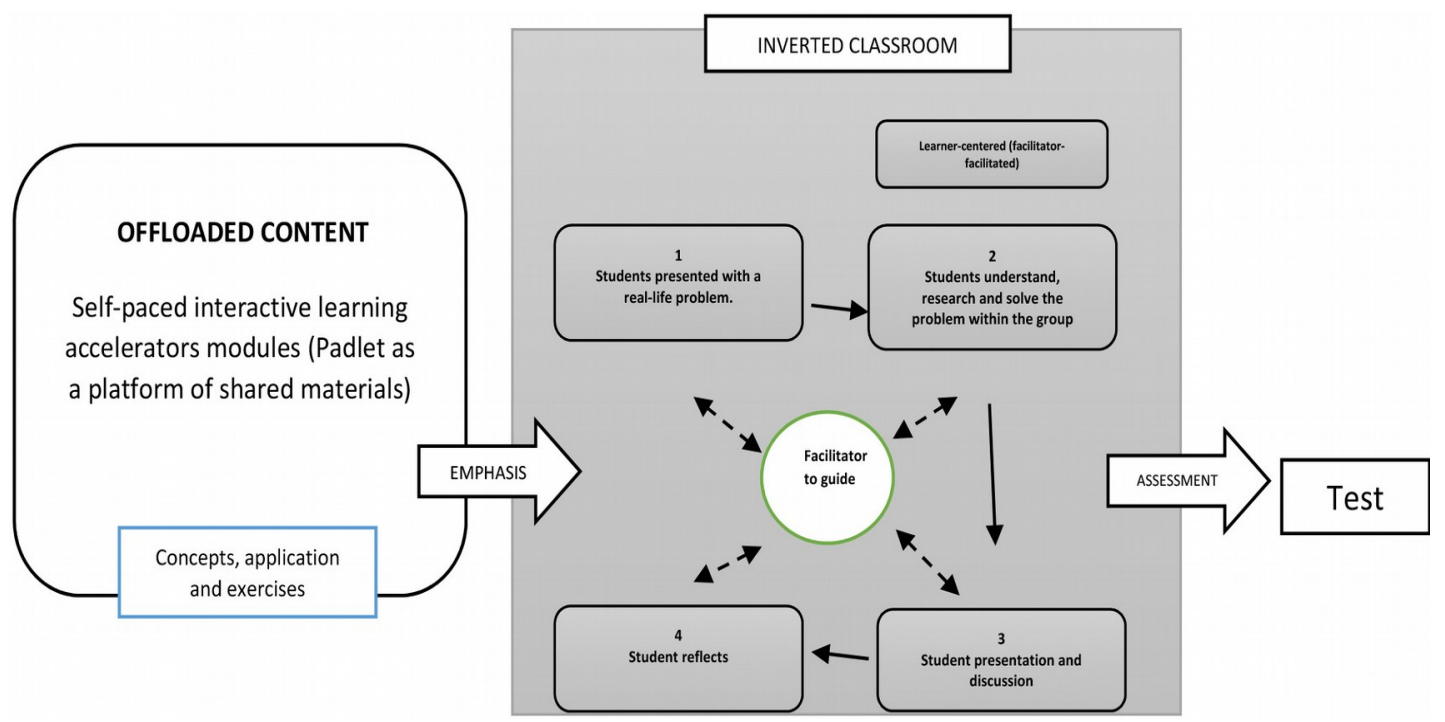

Figure 2. Inverted classroom format for the experimental group 
Step 3 (Students presentation and discussion). All the relevant information gathered from prior knowledge, online article, video and textbook will be presented in a 10 to 15 minutes presentation for each group.

Step 4 (Students reflect). In this step, students will talk and reflect within themselves and facilitator for what they have gained during the process to solve the problem and from the topics itself.

Towards the end of every module, a test was given to students of both controlled and experimental group. The questions in the test are reflections of the topic and similar for both groups.

\subsection{Study Analysis}

All data were analysed using statistical software SPSS version 23. Mann-Whitney U-test was used to test for differences in term of mean marks of students' performance in both pre- and post-test between the experimental and control group.

\section{Results}

Table 2 shows the distributions of students' Physics SPM grades for both the control and experimental group. From those of 33 students in control group, the highest number of student is those who scored B+ in Physics SPM 2017 with 14 students, followed by A- (11 students), B (6 students), and A+ (2 students). On the other hand, among the 43 students in the experimental group, the highest number of students is those who scored A- in Physics SPM 2017 with 17 students, followed by B+ (16 students), B (5 students), A (3 students), and A+ ( 2 students). The importance of this grade distribution is to show that both groups do not have a bias in terms of prior existing knowledge in physics. They were all fresh entry pre-university students who have some basic knowledge in physics from their secondary school learning.

To find out the students' prior knowledge on the integrated classroom, a question in the form of "Yes" or "No" was asked in the test. Table 3 shows that 9 students from 33 students in the control group have prior knowledge on the integrated classroom and 24 others have no prior knowledge. Meanwhile, for experimental group, 9 students had prior knowledge on the integrated classroom and 34 others did not have any relevant knowledge. Percentage shown in Table 3 shows evident that majority of students both in control and experimental group nearly do not know integrated classroom. While taking the pre-test at the beginning of the module, students are not expected to know the answers to all of the questions; however, they should be expected to utilize previous knowledge to predict rational answers. When taking the post-test at the end of the module, students should be expected to answer more questions correctly based on an increase in knowledge and understanding.

\begin{tabular}{|c|c|c|}
\hline Group & Grade & Frequency (N) Percentage (\%) \\
\hline \multirow{4}{*}{ Control } & $\mathrm{A}+$ & $2(6.1)$ \\
\cline { 2 - 3 } & $\mathrm{A}$ & $0(0)$ \\
\cline { 2 - 3 } & $\mathrm{A}-$ & $11(33.3)$ \\
\cline { 2 - 3 } & $\mathrm{B}+$ & $14(42.4)$ \\
\cline { 2 - 3 } & $\mathrm{B}$ & $6(18.2)$ \\
\cline { 2 - 3 } & Total & $33(100)$ \\
\hline \multirow{5}{*}{ Experimental } & $\mathrm{A}+$ & $2(4.7)$ \\
\cline { 2 - 3 } & $\mathrm{A}$ & $3(7.0)$ \\
\cline { 2 - 3 } & $\mathrm{A}-$ & $17(39.5)$ \\
\cline { 2 - 3 } & $\mathrm{B}+$ & $16(37.2)$ \\
\cline { 2 - 3 } & $\mathrm{B}$ & $5(11.6)$ \\
\cline { 2 - 3 } & Total & $43(100)$ \\
\hline
\end{tabular}

Table 2. Distributions of students' Physics SPM grades for control and experimental group 


\begin{tabular}{|l|c|r|r|}
\hline \multicolumn{2}{|c|}{ Group } & Frequency & \multicolumn{2}{|c|}{ Percentage (\%) } \\
\hline \multirow{3}{*}{ Control } & Yes & 9 & 27.3 \\
\cline { 2 - 5 } & No & 24 & 72.7 \\
\cline { 2 - 5 } & Total & 33 & 100 \\
\hline \multirow{3}{*}{ Experimental } & Yes & 9 & 20.9 \\
\cline { 2 - 5 } & No & 34 & 79.1 \\
\cline { 2 - 5 } & Total & 43 & 100 \\
\hline
\end{tabular}

Table 3. Distributions of students on the knowledge of integrated classroom for control and experimental group
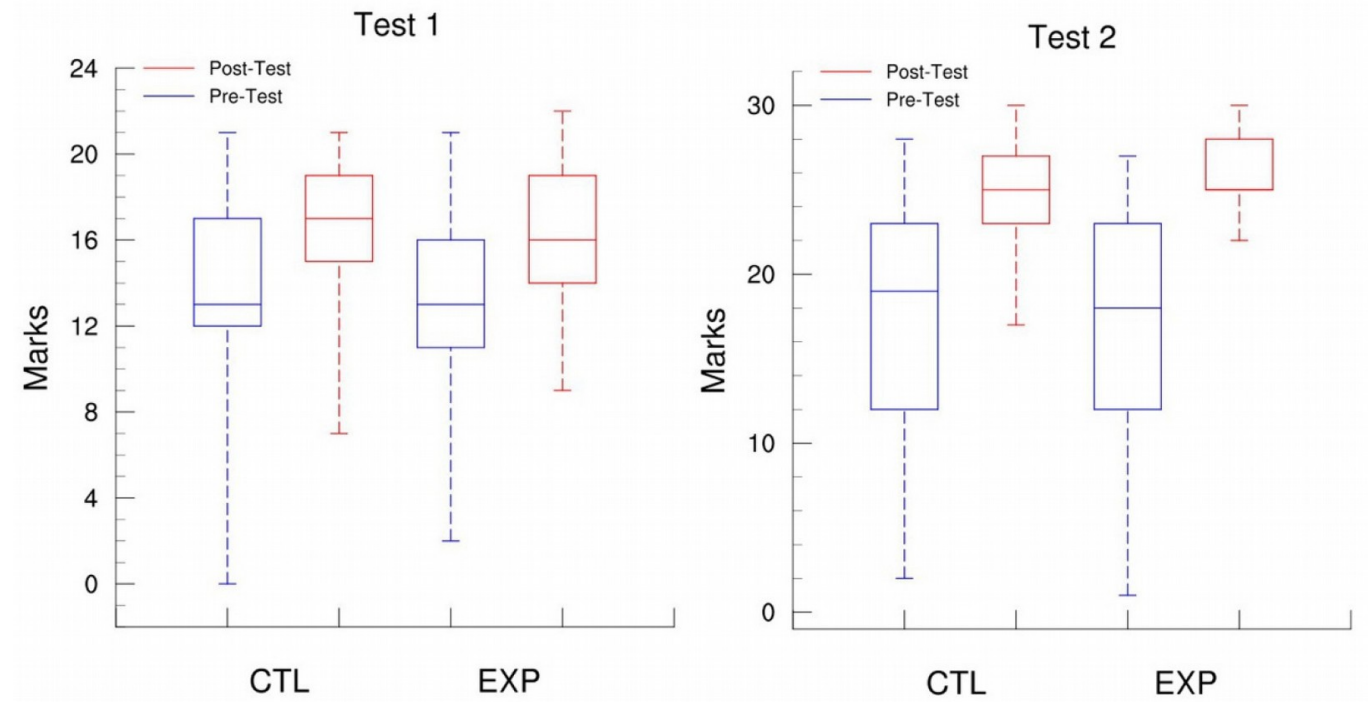

Figure 3. Box-plot of pre- and post-test of Test 1 and Test 2 from control (CTL) and experimental (EPX) group

\begin{tabular}{|c|r|r|}
\hline & Test 1 & \multicolumn{2}{|c|}{ Test 2 } \\
\hline Mann-Whitney U & 644.500 & 397.000 \\
\hline Asymp. Sig (2-tailed) & .495 & .001 \\
\hline
\end{tabular}

Table 4. Mann-Whitney $U$ test analysis for Test 1 and Test 2 from the control and experimental group

Figure 3 present the box plot of the pre- and post-test of Test 1 and Test 2 from control and experimental group. The results were interpreted using Mann-Whitney $U$ test. In Test 1 and Test 2, posttest remarks improvement in the mean marks scored for both groups. The total marks for Test 1 and Test 2 is 29 and 44 respectively. On average in Test 1, control group scored a mean of $13.0 \pm 5.0$ in pre-test and $16.6 \pm 2.8$ in post-test; experimental group scored a mean of $12.2 \pm 4.6$ in pre-test and $15.9 \pm 3.0$ in post-test. Slightly better improvement is observed in Test 2 where control group scored a mean of $16.6 \pm 7.3$ marks in pre-test and $24.0 \pm 3.1$ marks in post-test; experimental group scored a mean of $16.1 \pm 6.6$ in pre-test and $26.0 \pm 2.0$ in post-test.

According to Table 4, it shows that there is no significant difference in terms of mean marks in Test 1 between the control and experimental group with $\mathrm{U}=644.500$. The mean marks for both groups is nearly the same before the implementation either for the inverted classroom or traditional classroom. However, there is a significant difference in the mean marks of post-test in Test 2 between the control and experimental group for $\mathrm{U}=397.000$. This shows that there is a significant improvement in the mean marks of the experimental group after the intervention of the inverted classroom.

\section{Discussions}

This study was carried out to examine the effectiveness of the inverted classroom approach adapted in pre-university physics classroom on topics of classical mechanics. Generally, information about the percentage of students with prior knowledge of integrated classroom for control and experimental group 
is one of the rules out of factor of students' perception of a new teaching method between the control and experimental group. It is also entirely truthful to assume that most of the students experience their first-time involvement in an inverted classroom for the experimental group. While some students did hear and probably experienced the integrated classroom during high school, but this is inevitable due to the diversity of our students from different backgrounds.

Based on the results of the study, it is found that the inverted classroom implementation method is effective for the work, energy and power topics. This is shown in Test 2 where there is a significant increase in student achievement in the experimental group on the topic, this is in line with students' positive improvement in Physics among Palestinian high school students after flipped classroom implemented (Atwa, Din \& Hussin, 2016). However, for the topic of Force, Momentum and Impuls, there was no significant change in student achievement for the two groups shown in Test 1 . The findings were supported in Bates and Galloway (2012) study for the topic of Force, Momentum and Impuls is a difficult topic for students to master, mainly in Newtons Law sub topics. This topic requires time to learn by the students and as this topics involves various type of calculations, (Bates \& Galloway, 2012). Similarly show in study by Clark (2015), which flipped classroom was implemented in mathematics classroom and show no significant changes in terms of academic performance. However, it is prove that the inverted classroom implementation is a quality learning approach can used in physics teaching and learning (Aşıksoy \& Özdamlı, 2016; Bates \& Galloway, 2012).

Other than that, the findings of this study highlighted the promising use of inverted classroom on other basic topics of physics classroom in pre-university level. The results are also in good agreement with other previous studies such as Cagande and Jugar (2018) in which they show that inverted classroom had a positive impact on students' understanding of kinematics graphs. Capone et al. (2017) also reported the similar findings where they implemented inverted classroom in difficult topics of physics, i.e. quantum mechanics and results with students gain benefit through this approach.

\section{Conclusion and Future Development}

This study has shown that the performance of pre-university students can be benefited from the inverted classroom. The outcome of the study is consistent with past literature on the inverted classroom in physics. Potential future study of this is the extension to a larger size of students and more extended period of implementation. Also, the approach is also possible to use in other basic topics or difficult topics such as quantum mechanics.

\section{Declaration of Conflicting Interests}

The author declared no potential conflicts of interest with respect to the research, authorship, and/or publication of this article.

\section{Funding}

This research was fully funded from University Malaysia Sabah under research code SBK0294-SSI-2016 and this paper was partially funded under research code SLB0148-2017.

\section{References}

Assıksoy, G., \& Özdaml, F. (2016). Flipped Classroom adapted to the ARCS Model of Motivation and applied to a Physics Course. Eurasia Journal of Mathematics, Science \& Technology Education, 12(6), 1589-1603.

Atwa, Z., Din, R., \& Hussin, M. (2016). Effectiveness of Flipped Learning In Physics Education on Palestinian High School Students' Achievement. Journal of Personalized Learning, 2(1), 73-85.

Baepler, P., Walker, J.D., \& Driessen, M. (2014). It's not about seat time: Blending, flipping, and efficiency in active learning classrooms. Journal of Computers \& Education Elsevier, 78, 227-276.

https://doi.org/10.1016/j.compedu.2014.06.006 
Bates, S., \& Galloway, R. (2012). The inverted classroom in a large enrolment introductory physics course: A case study. In Proceedings of the HEA STEM Learning and Teaching Conference.

Bishop, J.L., \& Verleger, M.A. (2013). The Flipped Classroom: A Survey of the Research. Journal of American Society for Engineering Education, 30, 1-18.

Brown, R.G. (2013). Introductory Physics I: Elementary Mechanics.

Cagande, J.L.L., \& Jugar, R.R. (2018). The flipped classroom and college physics students' motivation and understanding of kinematics graphs. Issues in Educational Research, 28(2), 288-307.

Capone, R., Sorbo, M.R.D., \& Fiore, O. (2017). A Flipped Experience in Physics Education Using CLIL Methodology. Eurasia Journal of Mathematics Science and Technology Education, 13(10), 6579-6582. https://doi.org/10.12973/ejmste/77044

Chua, S.M.J., \& Lateef, F. (2014). The Flipped Classroom: Viewpoints in Asian Universities. Education in Medicine Journal, 6(4), 20-26. https://doi.org/10.5959/eimj.v6i4.316

Clark, K.R. (2015). The Effects of the Flipped Model of Instruction on Student Engagement and Performance in the Secondary Mathematics Classroom. The Journal of Educators, 12(1), 91-115.

https://doi.org/10.9743/JEO.2015.1.5

Garza, S.A. (2014). The Flipped Classroom Teaching Model and Its Use for Information Literacy Instruction. Journal of Communications in Information Literacy, 8(1), 6-22. https:/ / doi.org/10.15760/comminfolit.2014.8.1.161

McDermott, L.C., \& Redish, E.F. (1999). Resource letter: PER-1: Physics education research. American Journal of Physics, 67, 755. https://doi.org/10.1119/1.19122

Mason, G.S., Shuman, T.R., \& Cook, K.E. (2013). Comparing the Effectiveness of an InvertedClassroom to a Traditional Classroom in an Upper-Division Engineering Course. IEE Transactions on Education, 56(4), 430-435. https://doi.org/10.1109/TE.2013.2249066

O'Flaherty, J., \& Philips, C. (2015). The use of flipped classrooms in higher education: A scoping review. The Journal of Internet and Higher Education Elsevier, 25(2015), 85-95. https:/ /doi.org/10.1016/j.iheduc.2015.02.002

Talbert, R. (2012). Inverted Classroom. Journal of Education Reform, 9(1), 1-19,

Uzunboylu, H., \& Karagözlü, D. (2017). The Emerging Trend of the Flipped Classroom: A Content Analysis of Published Articles between 2010 and 2015. Journal of Revista de Educación a Distancia, 54(4), 1-13.

https://doi.org/10.6018/red/54/4

\author{
Published by OmniaScience (www.omniascience.com) \\ Journal of Technology and Science Education, 2019 (www.jotse.org)
}

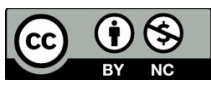

Article's contents are provided on an Attribution-Non Commercial 4.0 Creative commons International License. Readers are allowed to copy, distribute and communicate article's contents, provided the author's and JOTSE journal's names are included. It must not be used for commercial purposes. To see the complete licence contents, please visit https://creativecommons.org/licenses/by-nc/4.0/. 